\title{
Preparation of SiC powders by carbothermal reduction with bamboo charcoal as renewable carbon source
}

\author{
Xingzhong GUO, Lin ZHU, Wenyan LI, Hui YANG ${ }^{*}$ \\ Department of Materials Science and Engineering, Zhejiang University, Hangzhou 310027, China
}

Received: January 23, 2013; Revised: February 24, 2013; Accepted: February 27, 2013

(C) The Author(s) 2013. This article is published with open access at Springerlink.com

\begin{abstract}
Bamboo charcoal was expected to be a renewable carbon source for carbide materials in carbothermal reduction because of its superior characteristics. SiC powders with characteristic shapes were fabricated by carbothermal reduction with industrial silica sol and bamboo charcoal particles as silicon and carbon sources respectively, and the effects of reacting temperature and time on shape evolutions and properties of the as-prepared $\mathrm{SiC}$ powders were investigated. The silica sol/bamboo charcoal system was firstly transformed into $\mathrm{SiO}_{2} / \mathrm{C}$ system by the transition of silica sol and graphitization of bamboo charcoal, and the carbothermal reduction between $\mathrm{SiO}_{2}$ and $\mathrm{C}$ occurred at/above $1600{ }^{\circ} \mathrm{C}$. The characteristic shapes of $\mathrm{SiC}$ particles were transformed from string-beads-like to dumbbell-like and rod-like with the increase of reacting temperature. The prepared $\mathrm{SiC}$ powders are expected to become new raw material for silicon carbide ceramic composites.
\end{abstract}

Keywords: carbides; chemical synthesis; X-ray diffraction (XRD); microstructure

\section{Introduction}

Carbides $\left(\mathrm{Me}_{x} \mathrm{C}_{y}, \mathrm{Me}=\mathrm{Si}, \mathrm{B}, \mathrm{Ti}, \mathrm{Zr}, \mathrm{W}\right.$, etc. $)$ are a whole family of advanced materials and have been widely applied in modern industrial fields because of their unique properties, such as high mechanical properties, good resistance to corrosion, and high thermal stabilities [1-3]. Carbothermal reduction is the preferred method for industrial synthesis of carbide powder materials [3-7]. Wherein, the choice of carbon source is one of the key conditions of the carbothermal reduction and also is the decisive factor for carbide synthesis. The present carbon resources mainly include petroleum products (e.g., carbon black, petroleum coke, asphalt), coal products (e.g., coke), graphite

\footnotetext{
* Corresponding author.

E-mail: yanghui@zju.edu.cn
}

mining, and other mineral resources [4-7]. These mineral carbons are exhaustible-type carbon sources, and there exist complex procedures, high energy consumption and serious environmental pollution in the production processes. Furthermore, the existing industrial processes of carbide materials generally have the fundamental problems, such as high synthesis temperature (up to $2400{ }^{\circ} \mathrm{C}$ ), energy consumption, impurities, uniform compositions, and acid-base washing [1-3]. Therefore, it is necessary to develop a new industrial carbon source and improve the industrial synthesis of carbide materials.

Bamboo charcoal is a new natural carbon material, which comes from bamboo carbonized in a high-temperature (about $700{ }^{\circ} \mathrm{C}$ ) and less-oxygen environment [8]. Compared with mineral carbons, the production process of bamboo charcoal is simple, and its development is competitive because of rich resource and fast growing of bamboo. More importantly, 
bamboo charcoal possesses superior features unmatched by other carbon sources: (1) high specific surface area (up to $700 \mathrm{~m}^{2} / \mathrm{g}$ ); (2) high carbon content (more than 95\%) and containing $\mathrm{Si}, \mathrm{Mg}, \mathrm{Ca}, \mathrm{P}, \mathrm{Al}$, and other trace elements; (3) unique graphitization and layered microcrystalline structure; (4) good electrical properties $\left(3.85 \Omega \cdot \mathrm{cm}\right.$ at $\left.1000{ }^{\circ} \mathrm{C}\right)$ [9]. Therefore, it is hopeful that bamboo charcoal is used as a new and renewable carbon source for the synthesis of carbide materials.

In this work, we demonstrate the synthesis of $\mathrm{SiC}$ powder material (as an example of carbide materials) by carbothermal reduction using bamboo charcoal as carbon source. The effects of reacting temperature and time on the synthesis of $\mathrm{SiC}$ powders and the shape evolutions of the $\mathrm{SiC}$ powders are carefully investigated.

\section{Materials and methods}

Industrial silica sol with $36 \mathrm{wt} \%$ solid content (Sinopharm Chemical Reagent Co. Ltd., Shanghai, China) and $0.5-2 \mu \mathrm{m}$ bamboo charcoal particles (Suichuang Biyan Bamboo Charcoal Co. Ltd., Suichuang, China) were used as silicon and carbon sources, respectively. The graphitization of bamboo charcoal was firstly carried out at $1600{ }^{\circ} \mathrm{C}, 1700{ }^{\circ} \mathrm{C}$ and $1800{ }^{\circ} \mathrm{C}$, each for $2 \mathrm{~h}$ in a vacuum furnace with $\mathrm{Ar}$ atmosphere. The detail of the preparation of $\mathrm{SiC}$ powders is as follows. The industrial silica sol and bamboo charcoal particles were mixed with the mass ratio of $15: 85$ (molar ratio $1: 1$ ). The mixture was mechanically stirred for $12 \mathrm{~h}$ after ultrasound for $30 \mathrm{~min}$, and then dried at $100{ }^{\circ} \mathrm{C}$ to form the silica sol/bamboo charcoal system. The carbothermal reduction of the complex system was carried out at $1400-1800{ }^{\circ} \mathrm{C}$ for $1-8 \mathrm{~h}$ in a vacuum furnace with $\mathrm{Ar}$ atmosphere.

The prepared $\mathrm{SiC}$ particles were identified by X-ray diffraction (XRD) method on a Rigaku D/max-RA X-ray Diffractometer using nickel-filtered $\mathrm{Cu} \mathrm{K} \alpha$ radiation in the range of $2 \theta=10^{\circ}-80^{\circ}$ with a scanning speed of $2\left(^{\circ}\right) / \mathrm{min}$. The morphology and microstructure of the particles were investigated using scanning electronic microscopy (SEM, HITACHI S-4800) and transmission electron microscopy (TEM, JEM1230).

\section{Results and discussion}

\subsection{Graphitization of bamboo charcoal}

As we known, the graphitization of bamboo charcoal occurs at high temperature [9]. Figure 1 shows the XRD patterns of bamboo charcoal after heat treatment at different temperatures. It is noted that bamboo charcoal is amorphous, but there is a little crystalline graphite- $2 \mathrm{H}$ in it, indicating the existence of graphitization during the carbonation of bamboo. The major phase of bamboo charcoal is graphite-2H (JCPDS 41-1487), with the existence of some 3C-SiC (JCPDS 29-1129). The graphite-2H is attributed to the graphitization of bamboo charcoal, and $3 \mathrm{C}-\mathrm{SiC}$ is the result of the reaction between graphite and residual silicon element in ash. After heat treatment, bamboo charcoal shows absolutely layered microcrystalline structure of graphite (as shown in Fig. 2). In the previous research [9-11], we have confirmed that the ash content is very low in bamboo charcoal, while there exist $\mathrm{K}, \mathrm{Si}, \mathrm{Cl}, \mathrm{Mg}, \mathrm{S}, \mathrm{P}, \mathrm{Al}, \mathrm{Na}$, and other trace elements in the ash. Wherein, Si element can directly join the carbothermal reaction of carbon and silicon, and $\mathrm{K}, \mathrm{Mg}, \mathrm{Na}$ and other elements can play a catalytic role in the reaction, which is beneficial to the decrease of reacting temperature.

\section{2 Characteristics of the prepared SiC powders}

Figure 3 shows the XRD patterns of the prepared $\mathrm{SiC}$ powders at different reacting temperatures and time.

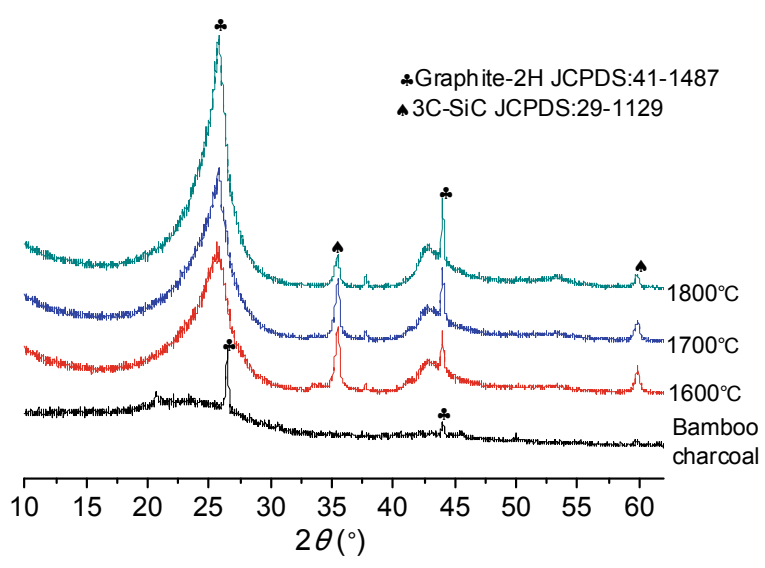

Fig. 1 XRD patterns of bamboo charcoal after heat treatment at different temperatures. 


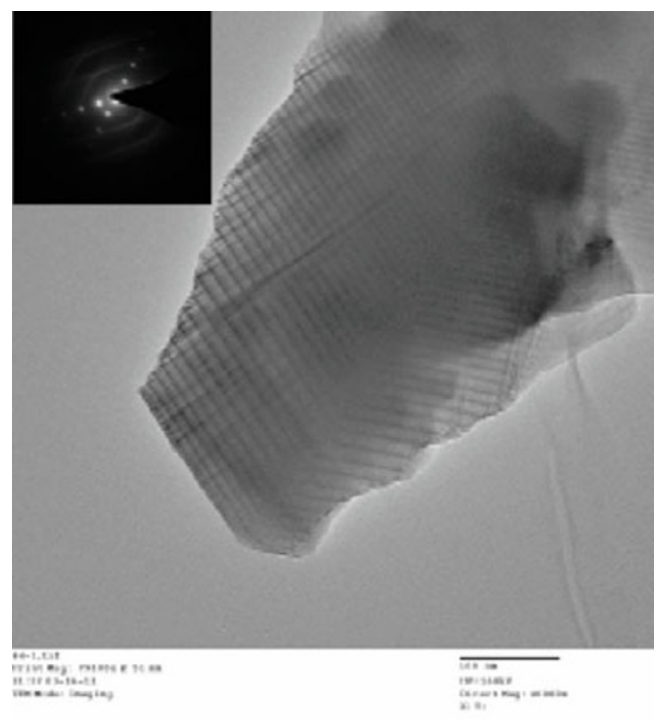

Fig. 2 TEM photo of bamboo charcoal heat-treated at $1800{ }^{\circ} \mathrm{C}$.
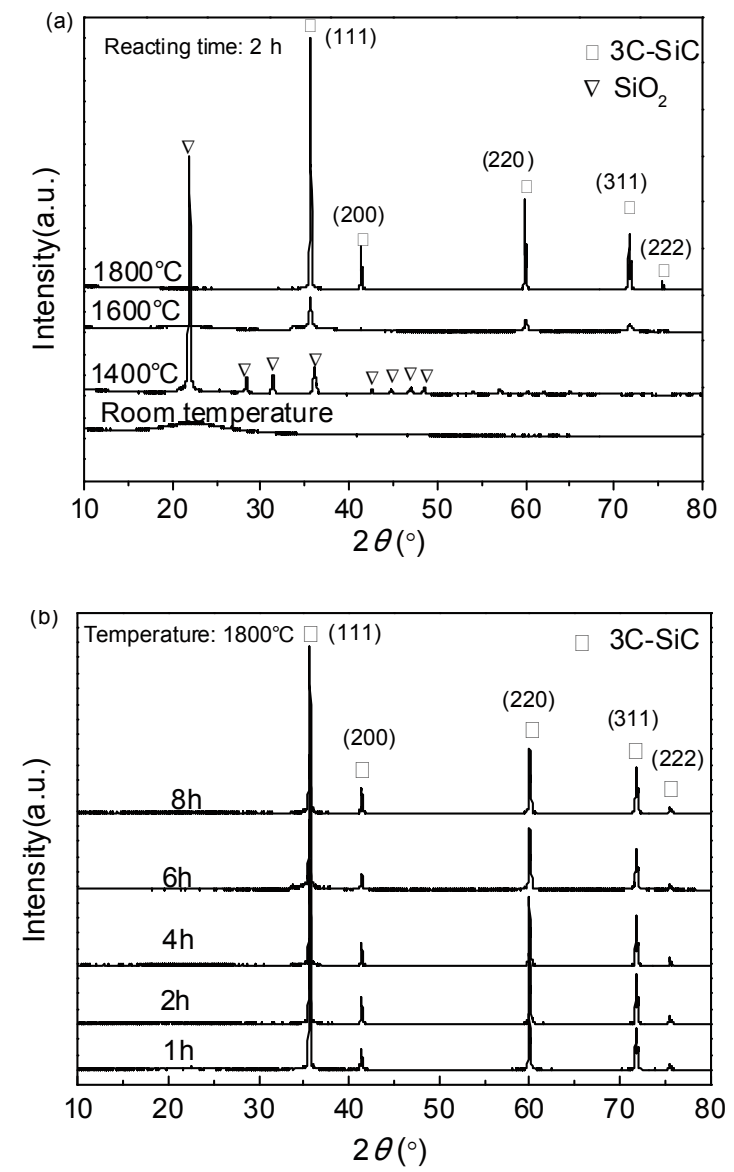

Fig. 3 XRD patterns of the prepared $\mathrm{SiC}$ powders at different reacting temperatures and time.

The silica sol/bamboo charcoal complex system is amorphous at room temperature. It indicates that the system is constructed by amorphous bamboo charcoal particles and attaching $\mathrm{SiO}_{2}$ xerogel. At $1400{ }^{\circ} \mathrm{C}$, there is more $\mathrm{SiO}_{2}$ phase in the system, while no $\mathrm{SiC}$ phase exists, which indicates that carbothermal reduction does not occur at/below $1400{ }^{\circ} \mathrm{C}$. Because of the graphitization of bamboo charcoal (Fig. 1), the complex system is firstly transformed into $\mathrm{SiO}_{2} / \mathrm{C}$ system. At $1600{ }^{\circ} \mathrm{C}$, the diffraction intensity of $\mathrm{SiO}_{2}$ phase decreases, and $3 \mathrm{C}-\mathrm{SiC}$ (i.e., $\beta$-SiC) appears, inferring the occurrence of carbothermal reaction. At $1800{ }^{\circ} \mathrm{C}, 3 \mathrm{C}-\mathrm{SiC}$ becomes a unique phase with high diffraction intensity, indicating complete crystal growth. With the increase of reacting time (Fig. 3(b)), there is only $3 \mathrm{C}$-SiC phase in all the samples for different reacting time, and the intensity of the same five diffraction peaks heightens with the increase of reacting time.

Compared with the purchased $\mathrm{SiC}$ nanopowders, the as-prepared $\mathrm{SiC}$ particles have the same five characteristic diffraction peaks $\left(2 \theta=35.56^{\circ}, 41.06^{\circ}\right.$, $60.06^{\circ}, 71.84^{\circ}$ and $75.64^{\circ}$ ) in the XRD patterns, confirming the pure $3 \mathrm{C}-\mathrm{SiC}$ phase. From Fig. 3, it is also found that the relative ratios of $(111) /(311)$ and $(220) /(311)$ reflections of the prepared $\mathrm{SiC}$ powders are larger than the standard values in JCPDS card No. 29-1129, especially for the $(111) /(311)$ ratio, confirming the preferential orientation growth in the [111] direction. Burda et al. have previously reported that each $\mathrm{SiC}$ molecule is a single crystal grain, which grows in a preferential crystallographic direction, i.e., [111] direction, because the (111) plane has the lowest surface energy among the $\mathrm{SiC}$ surface planes [12-16].

Figure 4 shows the infrared (IR) spectra of the as-prepared $\mathrm{SiC}$ particles at different reacting temperatures and time. From Fig. 4(a), the strong peaks near $1094.34 \mathrm{~cm}^{-1}$ and $482.14 \mathrm{~cm}^{-1}$ are assigned as $\mathrm{Si}-\mathrm{O}-\mathrm{Si}$ stretching and anti-stretching vibrations at $1400{ }^{\circ} \mathrm{C}$, indicating the existence of $\mathrm{SiO}_{2}$. The peak near $781.77 \mathrm{~cm}^{-1}$ found in the IR spectra is attributed to $\mathrm{Si}-\mathrm{C}$ stretching vibration, implying the generation of $\mathrm{SiC}$ at this temperature [11]. The peak near $1631.63 \mathrm{~cm}^{-1}$ is the result of $\mathrm{C}-\mathrm{C}$ stretching vibration, and the peak near $3422.89 \mathrm{~cm}^{-1}$ is attributed to $\mathrm{O}-\mathrm{H}$ vibration of bridging oxygen in the $\mathrm{H}_{2} \mathrm{O}$ molecule. At $1600{ }^{\circ} \mathrm{C}$, there are still $\mathrm{Si}-\mathrm{O}-\mathrm{Si}$ stretching and anti-stretching vibrations, but $\mathrm{Si}-\mathrm{C}$ stretching vibration at $781.77 \mathrm{~cm}^{-1}$ becomes strong, indicating the production of more $\mathrm{SiC}$. At $1800{ }^{\circ} \mathrm{C}$, it is found that the $\mathrm{Si}-\mathrm{O}-\mathrm{Si}$ stretching and anti-stretching vibration peaks have disappeared, indicating that there is no 

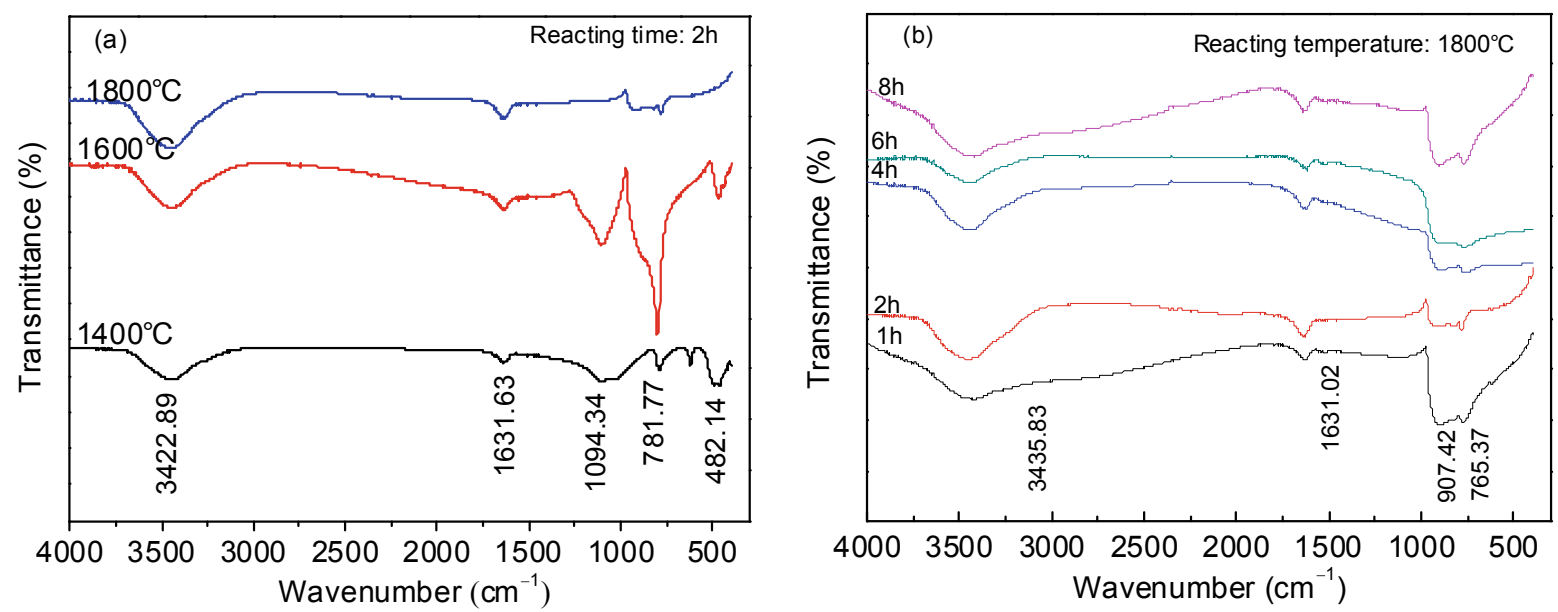

Fig. 4 IR spectra of the prepared $\mathrm{SiC}$ powders at different reacting temperatures and time.

existence of $\mathrm{SiO}_{2}$ in the prepared $\mathrm{SiC}$. With the increase of reacting time (Fig. 4(b)), the stretching vibration peaks of $\mathrm{Si}-\mathrm{C}$ gradually sharp. This similarly proves that the growth of $\mathrm{SiC}$ becomes more complete, which coordinates with the XRD results.

\section{3 Microstructure of the as-prepared SiC powders}

Figure 5 shows the SEM images of the prepared $\mathrm{SiC}$
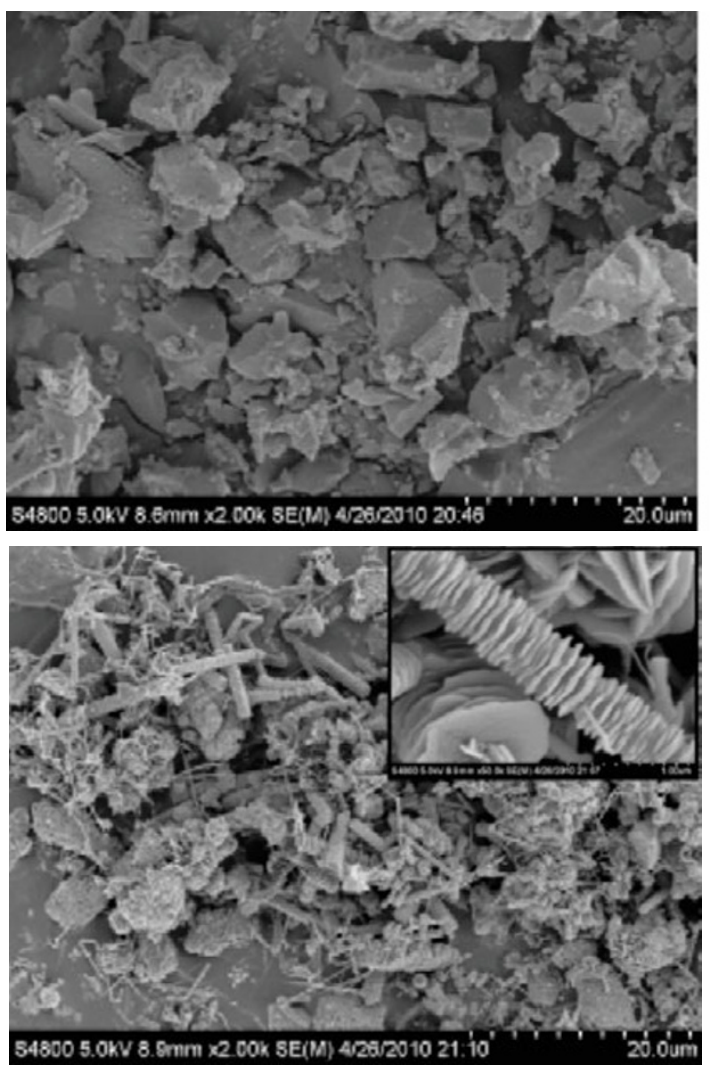

powders at different reacting temperatures for $2 \mathrm{~h}$. It is observed that there are mainly micron-sized bamboo charcoal particles at room temperature, and $\mathrm{SiO}_{2}$ nanoparticles attach on the surface of bamboo charcoal. Both particles contact each other to form the aggregates with different sizes. At $1400{ }^{\circ} \mathrm{C}$, the aggregates become regular with large size and loose structure, and there exist some $\mathrm{SiO}_{2}$ whiskers in the aggregates (see the upper right inset of Fig. 5(b)). It
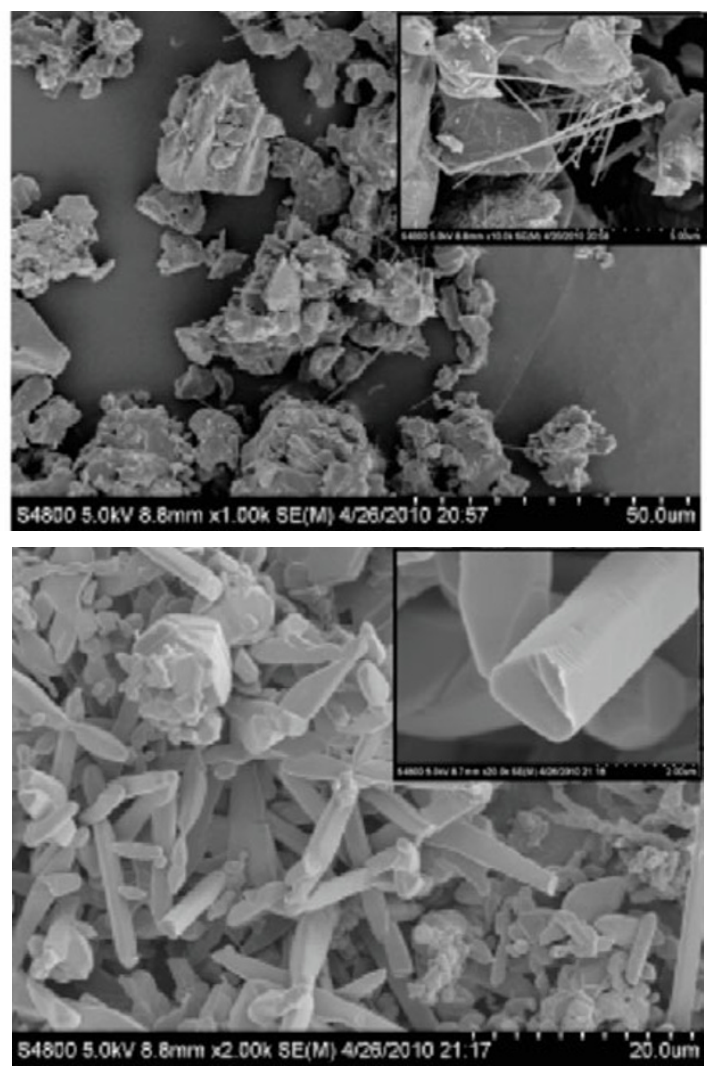

Fig. 5 SEM images of the prepared $\mathrm{SiC}$ at (a) room temperature, (b) $1400{ }^{\circ} \mathrm{C}$, (c) $1600{ }^{\circ} \mathrm{C}$, and (d) $1800{ }^{\circ} \mathrm{C}$. 
also confirms that silicon sol is firstly transformed into $\mathrm{SiO}_{2}$ nanoparticles or whiskers. At $1600{ }^{\circ} \mathrm{C}$, a lot of slice $\mathrm{SiC}$ crystals occur and some crystals stack to form string-beads-like or cluster-like crystals. It confirms that $\mathrm{SiO}_{2}$ nanoparticles firstly react with bamboo charcoal particles to form slice $\mathrm{SiC}$ crystals, and stack to form string-beads-like or cluster-like crystals by slice superposition. At $1800{ }^{\circ} \mathrm{C}$, most of $\mathrm{SiC}$ crystals are rod-like, and the surface is smooth and regular, indicating relatively complete crystal growth. The length size of crystal becomes larger and is about 5-20 $\mu \mathrm{m}$, confirming obvious orientation growth on the [111] direction, which coordinates with the XRD results.

Figure 6 shows the SEM images of the prepared SiC powders at $1800{ }^{\circ} \mathrm{C}$ for different reacting time. When the reaction time is $1 \mathrm{~h}$, there exist a lot of small $\mathrm{SiC}$ crystals. With the increase of reacting time, the small $\mathrm{SiC}$ crystals stack to form rod-like $\mathrm{SiC}$ crystals and the surface becomes smoother. It intuitively indicates that longer reacting time can heighten the conversion rate of silica and bamboo charcoal to $\mathrm{SiC}$ and improve the growth of complete rod-like crystals.

Figure 7 shows characteristic TEM images and selected area electron diffraction (SAED) patterns of three typical SiC crystals. The SAED patterns and the clear surface of this 1D structure indicate a high degree of crystallinity. The observation of typical $\mathrm{SiC}$ crystals is attributed to the apparent orientation growth in the [111] direction, irregular stacking area, and stacking faults, which is similar to the $\beta$-SiC whisker $[15,16]$.

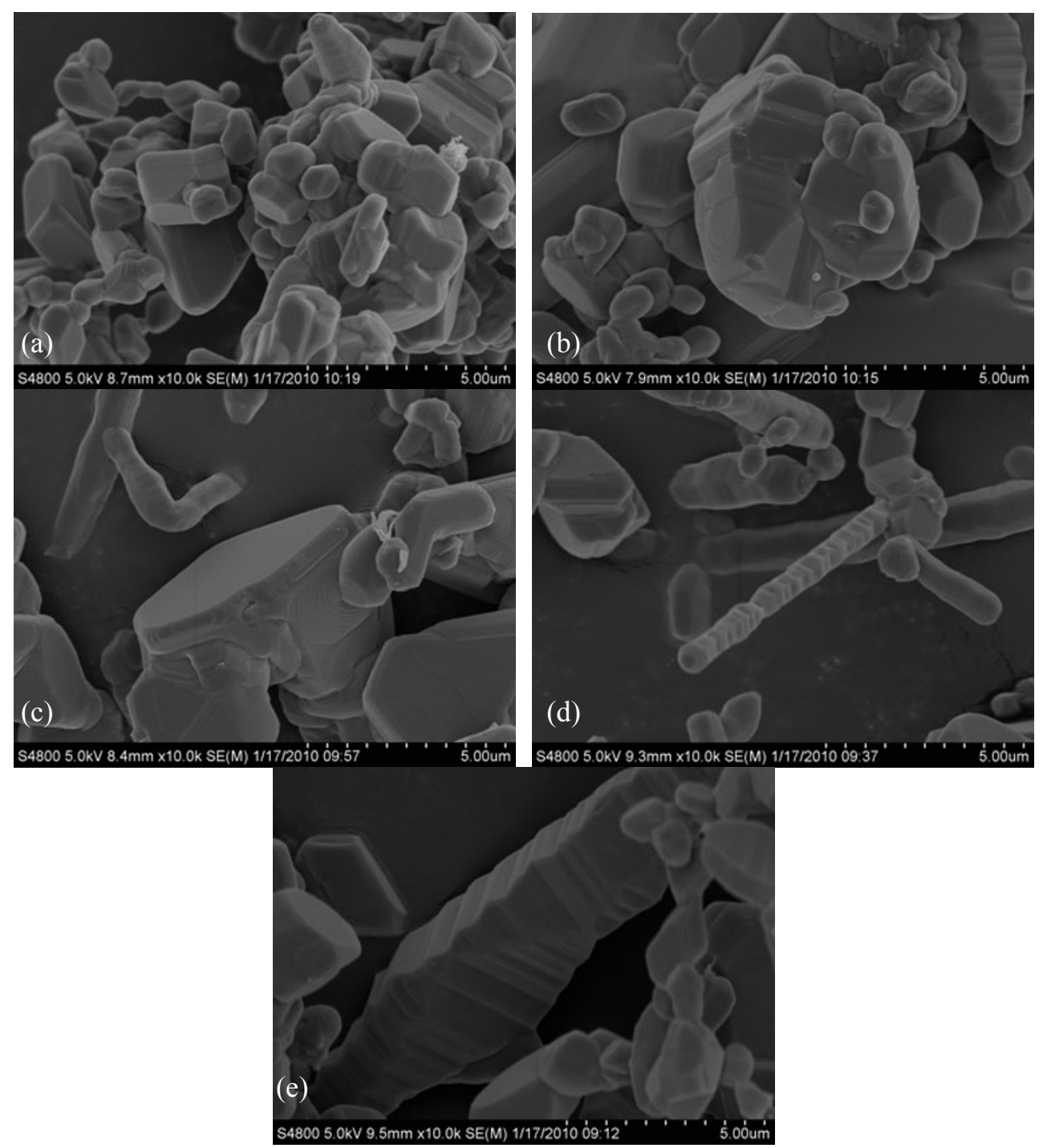

Fig. 6 SEM images of the prepared $\mathrm{SiC}$ at $1800{ }^{\circ} \mathrm{C}$ for (a) $1 \mathrm{~h}$, (b) $2 \mathrm{~h}$, (c) $4 \mathrm{~h}$, (d) $6 \mathrm{~h}$, and (e) $8 \mathrm{~h}$. 


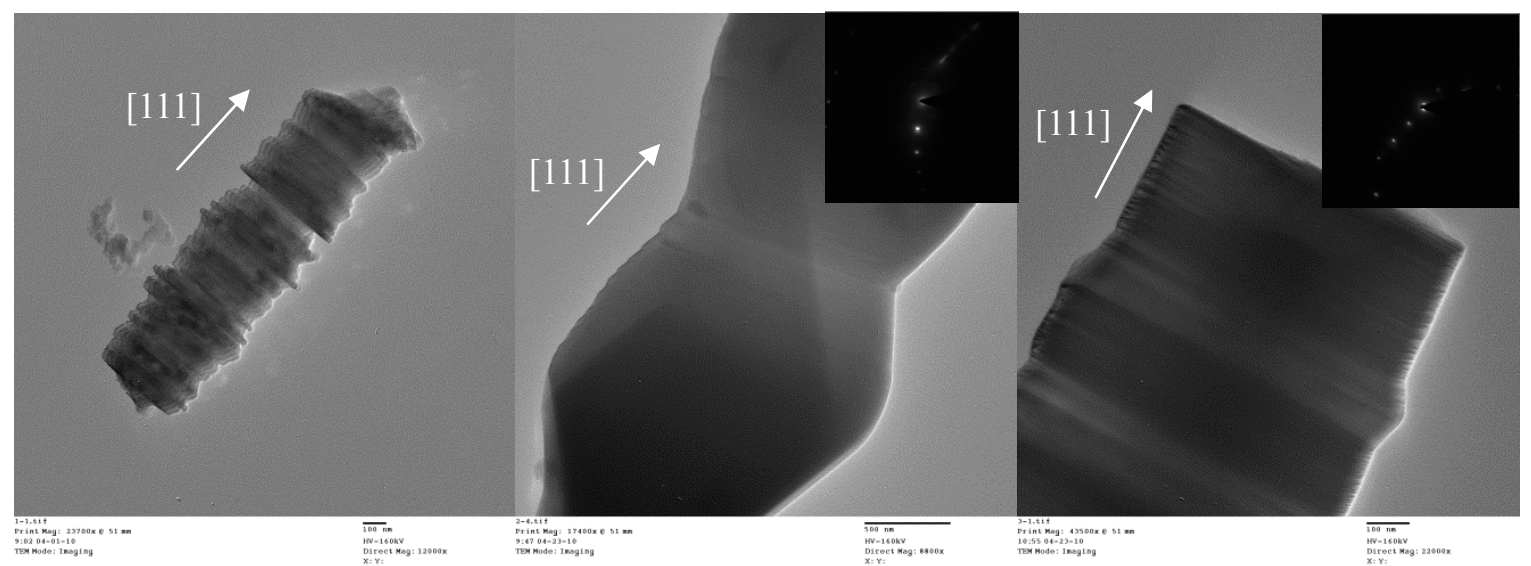

Fig. 7 TEM images and SEAD patterns of typical SiC crystals.

\section{4 Appearance of the as-prepared SiC powders}

The appearance of the prepared $\mathrm{SiC}$ powders at $1800{ }^{\circ} \mathrm{C}$ or $2 \mathrm{~h}$ shows gray-green color (shown in Fig. 8), which is similar to the industrial high-quality $\mathrm{SiC}$ powders prepared using petroleum coke and silica as main raw materials and salt as catalyst [17]. The present industrial $\mathrm{SiC}$ powders are prepared by Acheson method, and the shape of $\mathrm{SiC}$ powders is relatively simple (most is blocky or granular after grinding). In this work, different characteristic shapes such as rod-like and granular can be obtained in the $\mathrm{SiC}$ powders simultaneously. It proves that the as-prepared $\mathrm{SiC}$ powders possess superior characteristics such as high purity, hardness and strength. It will provide high-quality raw materials for the preparation of $\mathrm{SiC}$-based ceramic composites.

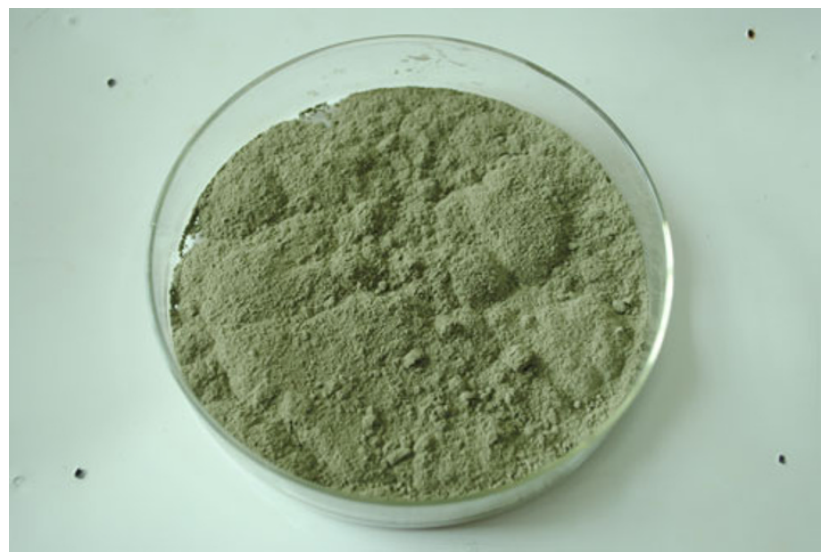

Fig. 8 Photo of the as-prepared $\mathrm{SiC}$ powders by carbothermal reduction at $1800{ }^{\circ} \mathrm{C}$ for $2 \mathrm{~h}$.

\section{Conclusions}

The SiC powders with characteristic shapes were fabricated by carbothermal reduction with industrial silica sol and bamboo charcoal as silicon and carbon sources, respectively. Silica sol/bamboo charcoal system was firstly transformed into $\mathrm{SiO}_{2} / \mathrm{C}$ system by the transition of silica sol and graphitization of bamboo charcoal. The carbothermal reduction between $\mathrm{SiO}_{2}$ and $\mathrm{C}$ occurred at/above $1600{ }^{\circ} \mathrm{C}$, and generated the slice $\mathrm{SiC}$ crystals. The slice $\mathrm{SiC}$ crystals stacked and grew with the increase of temperature, and the characteristic shapes were transformed from string-beads-like into dumbbell-like and rod-like. The gray-green $\mathrm{SiC}$ powders with characteristic shapes are expected to be a new raw material for the silicon carbide ceramic composites.

\section{Acknowledgements}

This work is supported by the High Science \& Technique Brainstorm Project of Zhejiang Province of China (No. 2012C01032-1), Zhejiang Key Innovation Team Projects (No. 2009R50010), and Innovation Fund for Technology Based Firms (No. 12C26113303061).

Open Access: This article is distributed under the terms of the Creative Commons Attribution Noncommercial License which permits any noncommercial use, distribution, and reproduction in any medium, provided the original author(s) and source are credited.

\section{References}

[1] Riley FL. Structural Ceramics: Fundamentals and 
Case Studies. Cambridge University Press, 2009.

[2] Basu B, Balani K. Advanced Structural Ceramics. John Wiley \& Sons, 2011.

[3] Singh D, Zhu DM, Zhou YC, et al. Eds. Design, Development, and Applications of Engineering Ceramics and Composites: Ceramic Transactions. John Wiley \& Sons, 2010.

[4] Narisawa M, Yasuda H, Mori R, et al. Silicon carbide particle formation from carbon black-Polymethylsilsesquioxane mixtures with melt pressing. J Ceram Soc Jpn 2008, 116: 121-125.

[5] Cui XL, Wang YH, Wang L, et al. Synthesis of nanometer-sized $\mathrm{TiC}$ and $\mathrm{SiC}$ from petroleum coke by reactive milling. Pet Sci Technol 2011, 19: 971-978.

[6] Sulardjaka, Jamasri, Wildan MW, et al. Method for increasing $\beta$-SiC yield on solid state reaction of coal fly ash and activated carbon powder. Bull Mater Sci 2011, 34: 1013-1016.

[7] Wang L, Hu XB, Xu XG, et al. Synthesis of high purity $\mathrm{SiC}$ powder for high-resistivity $\mathrm{SiC}$ single crystals growth. J Mater Sci Technol 2007, 23: 118-122.

[8] Asada T, Ishihara S, Yamane T, et al. Science of bamboo charcoal: Study on carbonizing temperature of bamboo charcoal and removal capability of harmful gases. J Health Sci 2002, 48: 473-479.

[9] Dai JL, Guo XZ, Yang H, et al. Study on the microstructure of bamboo charcoal. J Mater Sci Eng
2007, 25: 743-745 (in Chinese).

[10] Guo XZ, Zhu L, Yang H, et al. Effects of additives on the microstructure of synthesized SiC particles by using silica sol/bamboo charcoal system. Mater Lett 2012, 73: 133-135.

[11] Guo XZ, Zhang LJ, Yan LQ, et al. Preparation of silicon carbide using bamboo charcoal as carbon source. Mater Lett 2010, 64: 331-333.

[12] Burda C, Chen XB, Narayanan R, et al. Chemistry and properties of nanocrystals of different shapes. Chem Rev 2005, 105: 1025-1102.

[13] Yang GY, Wu RB, Pan Y, et al. Direct observation of the growth process of silicon carbide nanowhiskers by vapor-solid process. Physica $E$ 2007, 39: 171-174.

[14] Wu RB, Yang GY, Pan Y, et al. Prism-shaped SiC nanowhiskers. J Alloys Compd 2008, 453: 241-246.

[15] Dhage S, Lee HC, Hassan MS, et al. Formation of $\mathrm{SiC}$ nanowhiskers by carbothermic reduction of silica with activated carbon. Mater Lett 2009, 63: 174-176.

[16] Dhiman R, Johnson E, Morgen P. Growth of SiC nanowhiskers from wooden precursors, separation, and characterization. Ceram Int 2011, 37: 3759-3764.

[17] Sōmiya S, Inomata Y, Eds. Silicon Carbide Ceramics: Fundamental and Solid Reaction. London: Elsevier Applied Science, 1991. 